\title{
Design and Evaluation of a Predictive Powertrain Control System for a PHEV to Improve Fuel Economy and Emissions
}

Journal name

000(00):1-13

(C) The Author(s) 2010

Reprints and permission:

sagepub.co.uk/journalsPermissions.nav

DOI:doi number

http://mms.sagepub.com

\section{Amir Taghavipour, Nasser L.Azad, and John McPhee}

Systems Design Engineering Department, University of Waterloo, Ontario, Canada

\begin{abstract}
Amir Taghavipour
Amir Taghavipour received his BASc and MASc Degrees in Mechanical Engineering from Sharif University of Technology, Tehran, Iran, in 2007 and 2009. He is now a PhD student at the University of Waterloo, Department of Systems Design Engineering. His research interests are predictive automotive powertrain control, hybrid electric vehicles power management strategy design and optimization.
\end{abstract}

\section{Nasser Lashgarian Azad}

Nasser Lashgarian Azad is an Assistant Professor in Systems Design Engineering at the University of Waterloo. His primary research interests lie in modelling, estimation and control of complex dynamic mechanical and multi-domain physical systems, with special emphasis on advanced modelling and model reduction methods, sensitivity analysis techniques, non-linear and optimal control, with applications to advanced vehicle systems, such as modern automotive powertrains and vehicle dynamics control systems.

\section{John McPhee}

John McPhee is a Professor in Systems Design Engineering at the University of Waterloo, Canada, and the NSERC/Toyota/Maplesoft Industrial Research Chair in Mathematics-based Modelling and Design. His main area of research is multibody system dynamics, with principal application to the analysis and design of vehicles, mechatronic devices, biomechanical systems, and sports equipment. He is a Fellow of the American Society of Mechanical Engineers and the Canadian Academy of Engineering. He was the Executive Director of the Waterloo Centre for Automotive Research until 2009, after which he spent a sabbatical year at the Toyota Technical Center in Ann Arbor, Michigan. 


\begin{abstract}
In this article, a power management scheme for a plug-in power split hybrid electric vehicle (PHEV) is designed, based on the model predictive control (MPC) concept for charge depletion/charge sustenance (CDCS) and the blended mode strategies. The commands of MPC are applied to the powertrain components through appropriate low-level controllers: standard PI controllers for electric machines and sliding mode control for the engine torque control. The engine emissions minimization is a key factor to design the engine low-level controller. Applying this control package to a validated highfidelity model of a PHEV, developed in the MapleSim environment with a chemistry-based Lithium-ion battery model, results in considerable fuel economy and emissions performance.
\end{abstract}

Keywords

plug-in hybrid electric vehicles, power management scheme, model predictive control, blended mode control strategy, sliding mode control, engine emissions control, fuel economy

\title{
1. Introduction
}

Rising fuel costs and tightening regulations on emissions, as well as environmental concerns, are revolutionizing the automotive industry. The first step was developing hybrid electric vehicles to reduce the environmental footprint of gasoline engine powered vehicles. Other sources of energy in hybrid vehicle powertrains have made the engines smaller and more efficient, which leads to less emissions and better fuel economy for these vehicles.

With the development of advanced battery technologies, the energy storage capacity of batteries has significantly improved. The plug-in hybrid electric drive train is designed to fully or partially use the battery to displace part of the primary energy source (1). Plug-in hybrid electric vehicles (PHEVs) have larger battery storage in comparison to conventional hybrids. In PHEVs, the battery can be fully charged with conventional home electric plugs before starting off. In this way, the vehicle can go longer in the pure electric mode, so that the engine is shut off for a larger time period (2). This leads to a better fuel economy in plug-in hybrid vehicles in comparison to conventional hybrids. Moreover, most urban travels take place in a short mileage so the probability of having the engine always off will increase (3).

Among different architectures, the power-spilt architecture has a significant benefit, since it decouples the engine crankshaft from the road, and allows the electric machines to move the engine operation point to where fuel efficiency is maximized (4). However, the best architecture can operate poorly when using an inappropriate control scheme. One possible way to design a power management scheme for a PHEV is extending the strategies applied to conventional hybrid electric vehicles (5). Since the plug-in powertrain is different from conventional hybrid vehicles in terms of initial conditions and constraints, some modifications should be applied for the best performance.

In PHEVs, there is more flexibility in designing power management scheme, due to larger battery capacity. Different control schemes are proposed in the literature that can be divided into two main categories: rule-based and model-based schemes. Rule-based approaches put a constraint on the power split between different power sources on-board based on the current state of the powertrain (e.g., vehicle/engine speed, battery charge, power demand, etc.) through some maps, or rule bases (6). Then some rules can be applied to ensure that the states of the system are as close as possible to the desired scheme. The mentioned maps are constructed from engineering expertise and insight, or using more formal methods such as optimization (7) or fuzzy logic (8). Rule-based schemes are rigid and their performance is considerable for a known pattern of drive cycle but they are not optimized. It is possible to get this optimality by using model-based approaches. In model-based approaches, a simple and adequately accurate control-oriented model of the real plant is utilised for the

\footnotetext{
*Corresponding author; e-mail: a.taghavipour@gmail.com
} 
controls design. Model-based control approach is time-saving and cost-effective, because the design procedure is conducted through a single model of the whole system. Therefore, it results in an optimized and validated system for all possible operating conditions.

Based on the battery depletion profile, the power management scheme for PHEVs can be divided in two categories: charge depletion plus charge sustenance (CDCS) and the blended mode. In CDCS, the vehicle goes in pure electric mode first, so the battery is discharged from a high level, and when battery state of charge (SOC) drops to a reference value, the control strategy tries to keep it as close as possible to that level. This reference value is lower than what it is in an HEV. In fact, if demanded power in the first part of travel is more than what electric motor or battery can provide, the engine will compensate the remaining propulsion power. In the blended mode strategy, the engine tries to reduce the rate of battery discharge in order to delay the charge sustaining stage. So, in the blended mode strategy, the battery and the engine are used consistently during entire driving trip such that the battery SOC decreases continuously (9). For each of these mentioned categories, different control approaches can be considered.

(10) derived an optimal power management scheme for a plug-in hybrid vehicle (power-split architecture) based on stochastic dynamic programming (11).(12) demonstrated that the optimal scheme rations battery charge through blending the engine and battery power such that SOC reaches the minimum level exactly when the trip terminates, if the drive cycle is known a priori. Two algorithms - ECMS (Equivalent Consumption Minimization Strategy) and dynamic programming (DP) - are considered in (12) to optimize the power split between electrical and mechanical energy sources. The performance obtained using dynamic programming as a global optimal energy management scheme for a PHEV is used as the benchmark for evaluating an on-board implementable control scheme based on ECMS.

Some studies have addressed battery health-conscious power management scheme for PHEVs. For instance, (13) suggested that to minimize battery degradation, a PHEV power management scheme should first, deplete battery charge quickly, then blend the engine and battery power to avoid charge sustenance.

Some references (14),(15), (16), and (17) suggest that it is possible to improve the control scheme performance of PHEV if the trip information is determined a priori by means of recent advancements in intelligent transportation system (ITS) based on the use of global positioning system (GPS) and geographical information system (GIS).

Model predictive control (MPC) seems a proper method to exploit the potentials of modern concepts and to fulfill the automotive requirements. The success of MPC in industrial applications is due to its ability to handle processes with many manipulated and controlled variables and constraints on them in a systematic way (18). Furthermore, MPC allows for the specification of an objective function which is optimized by the controller. Other advantageous MPC features are the capability of dealing with time delays (19), of rejecting measured and unmeasured disturbances (20), and of taking advantage from future information (21). There is a philosophical attractiveness to MPC since it embodies both optimization and feedback adjustment. In fact, MPC has been developed to integrate the performance of optimal control with the robustness of feedback control (22). MPC determines the control input via receding horizon optimal control based on an open-loop model of the process, called prediction model. The prediction model is a compromise between simplicity and representativeness of the physics of the process. The prediction model used in MPC (as well as in any other model-based control design techniques) is usually very simple, yet representative enough to capture the main dynamical relations of the real plant. In other words, the prediction model should be control-oriented.

Application of MPC to hybrid vehicles has been investigated before. (23) proposed a real-time control system for different hybrid architectures using the MPC concept. (24), applied MPC to a power-split hybrid electric vehicle, ignoring the dynamics of the powertrain against other faster dynamics for the model inside the controller. They proposed that the fuel economies achieved with MPC are better than those reported by the rule-based PSAT simulation software. (25) applied MPC to a power-split plug-in hybrid electric vehicle and used dynamic programming as a benchmark for evaluating the power management scheme performance. 
As mentioned earlier, plug-in hybrid electric vehicles have the potential for considerable fuel consumption reductions, but possibly at the expense of increased tailpipe emissions due to multiple cold starts and improper use of the engine for PHEV specific operation (26). It seems that the catalyst temperature management for reduced tailpipe emissions is a challenging control problem due to the frequent and extended engine shut-down and catalyst cool-down (27).

Throughout the literature there are different approaches to address this emissions problem. For instance, it is possible to use a separate hardware in addition to the catalyst to resolve the concerns on different engine start events. In (28), the authors investigate the addition of hydrocarbon (HC) absorber traps and activated carbon fiber canister in traditional exhaust after-treatment system. These traps can store HC temporarily and release it after the temperature reaches the lightoff temperature of exhaust after-treatment device. Therefore, the $\mathrm{HC}$ will be catalyzed by exhaust after-treatment even at low temperatures. The same thing happens for NOx that is translated to $\mathrm{N}_{2}$.

A number of articles have presented models for a three-way catalytic converter (TWC) to describe the heat/mass transfer in the after-treatment system and conversion efficiency as a function of the catalyst brick temperature and air to fuel ratio (29),(30). These models are primarily used for design and evaluation and are too complex for the development of control algorithms. Using simpler models of catalyst conversion efficiency, makes it possible to design a specific model-based emissions control for the engine. For instance, (31) proposed a simplified model of an internal combustion engine to derive a sliding mode control law for emissions control. In (32) the authors used Pontryagin's Minimum principle (PMP) approach to do real-time optimal control of cold start via an experimentally verified control-oriented model of the engine.

In most optimization problems for hybrid vehicles, minimizing fuel consumption is the only objective, and emissions limitation is considered as a constraint of the process; as long as emissions are within predefined limits, it does not influence the optimization process (33). Recent HEV studies considered emission reduction as a part of the control objective and analyzed the trade-off between fuel economy and emissions (34),(35). Most of those considered minimization of fuel consumption and engine-out emissions instead of tailpipe emissions (34),(36). Although reducing engine emissions can reduce tailpipe emissions as well, it is not the key factor. Since the conversion efficiency of a cold catalyst is very low. Therefore, fast catalyst warm-up and sustainment are the key factors to minimizing tailpipe emissions (37). In (38) the authors designed a control scheme using multi-objective genetic algorithms to develop a fuzzy controller to reduce fuel consumption and emissions of a parallel hybrid electric vehicle simultaneously. In (39) a modified ECMS is proposed to include fuel consumption and also a NOx reduction control for a lightweight though-the-road architecture HEV. The control strategy has been able to reduce NOx emissions near to Euro 4 restrictions and also maintain $\mathrm{CO}$ and $\mathrm{HC}$ emissions below the restrictions of Euro 4 and 5 standards. (40) investigates the effect of an absorber which can substantially reduce the hydrocarbon and nitrogen oxide emissions by temporarily storing them until the three-way catalyst is sufficiently warm to remove them from the exhaust. It is shown that the mentioned absorber has a substantial effect on reducing emissions for a PHEV in comparison to an HEV.

(26) experimentally verifies a vehicle supervisory control system for a pre-transmission parallel PHEV powertrain architecture, where tailpipe emissions from a PHEV test platform have been reduced through the development and refinement of vehicle supervisory control methods. The focus of the enhancements was to replace high engine torque demands during starting with clean electric motor torque through some rule-based methods. This approach was proven to be very effective for the reduction of NOx emissions. However, the model-based control approaches suggest even better performance for different operating conditions. In (27), the authors used dynamic programming approach and came up with an adaptive supervisory powertrain controller (SPC) that optimally adjusts the engine on/off, gear-shift, and power-split strategies under various Energy-to-Distance Ratios (EDR) and catalyst temperature conditions for a pre-transmission parallel plug-in hybrid electric compact SUV in order to achieve near-optimal fuel economy and emission performance. Of course, the authors used a simple simulation model of the powertrain to evaluate their proposed scheme. Also, they assumed that air to fuel ratio and spark ignition timing of the engine are controlled for the optimal performance. 
In this research, we propose an optimal and real-time implementable power management scheme using the MPC concept including low-level controllers for Toyota Prius plug-in hybrid, with a more complicated dynamics of a power-split architecture in comparison to other configurations. For the engine low-level controller, sliding mode control approach is considered to make the engine follow the MPC-prescribed torque trajectory while maximizing HC conversion efficiency of a catalytic converter, which results from multiple engine starts, as mentioned before. This controller is robust and can guarantee a good performance in the real world experiment. For designing this power management scheme, both CDCS and blended mode strategies are investigated. Finally, we evaluate the performance of the proposed power management scheme by applying it to a high-fidelity model of Toyota Prius plug-in hybrid developed in MapleSim.The MapleSim model parameters are estimated by using the experimental database available in the Argonne National Laboratory Autonomie software, in order to make it close to the real system. The distinguishing part of this simulation model is a chemistry-based model of the Lithium-ion battery pack along with equation-based model of all powertrain components, which results in a more realistic evaluation of the power management scheme performance. Therefore, we come up with a more reliable trade-off between fuel economy and emissions using an optimal power management scheme for both CDCS and blended mode strategies.

The major contributions of this paper are listed as: non-linear MPC and sliding mode control application to design a power management system a PHEV, addressing fuel consumption reduction and emissions performance simultaneously as the main objectives of the control system, controls performance evaluation by using an equation-based and validated simulation model with chemistry-based battery model which is developed in MapleSim for a more realistic estimation of battery state, and improving PHEV fuel economy as well as reducing its emissions by controlling the engine air to fuel ratio.

The paper is organized as follows: At first, controls design procedure is presented. Since the control approaches are model-based, we introduce the control-oriented models used in each level, accordingly. After designing the power management scheme, its performance is evaluated by the powertrain high-fidelity model, which is introduced in section 5. Results of simulation, discussion and conclusion come afterwards.

\section{Supervisory Control}

The MPC approach is utilised to design a power management scheme for the PHEV considering CDCS and the blended mode strategies. The general design objective of MPC is to compute a trajectory of a future input to optimize the future behavior of the plant output. The optimization is performed within a limited time window based on the information of the plant at the start of the time window. In MPC there are three main requirements. The first is a sufficiently accurate model; the second is the assessment of current status of the system; and the third is the instrument of implementing the planned activities. There are some common expressions used in MPC: moving horizon window is the time interval in which the optimization is applied, and the length of this window is called the prediction horizon. It determines how far we wish to predict the future. The objective of solving an MPC problem is to find a vector that contains the variation of inputs in order to reach the desired trajectory of outputs. The length of this vector is called control horizon. Although the optimal trajectory of future control signal is completely described within the moving horizon window, if the actual control input to the plant only takes the first sample of the control signal, while neglecting the rest of the trajectory, we call this principle a receding horizon control (23). In the planning process, we need the state variables at a given time in order to predict the future. This information is either directly measured or estimated. A good dynamic model will give a consistent and accurate prediction of the future. Meanwhile an integrator is naturally embedded into the design, leading to the predictive control system tracking constant references and rejecting constant disturbances without steady-state errors. Another significant advantage of the MPC approach is that in implementation, it neither requires the steady-state information about the control nor the information about the steady state of the state variable. In each prediction window we need a cost function to be 
minimized that results in maximum fuel economy and tracking a predefined level of battery charge while following a drive cycle. The cost function is:

$$
\begin{gathered}
J(k)=\sum_{i=1}^{N_{p}}\left(\left(w_{1}\left(S O C_{r e f}(k+i)-S O C(k+i)\right)^{2}+w_{2}\left(\dot{m}_{f}(k+i)\right)^{2}\right)\right) \\
\left.+\sum_{j=1}^{N_{c}}\left(w_{3}\left(\Delta T_{g}(k+j)\right)^{2}\right)+w_{4}\left(\Delta T_{m}(k+j)\right)^{2}\right) .
\end{gathered}
$$

The first term is related to keeping the state of charge around the predefined reference $\left(S O C_{r e f}\right)$. The second term is for maximizing the fuel economy, where $\dot{m}_{f}$ is the rate of engine fuel consumption. Two last terms are considered for making control inputs as smooth as possible, where $\Delta T_{m}$ and $\Delta T_{g}$ are the variation of motor and generator torque. $w_{1}, w_{2}, w_{3}$, and

$w_{4}$ are weighting parameters chosen according to the predicted maximum value of the weighted variables. These weighting parameters have a significant effect on controller performance. Readers are referred to (41) for more details on determining weighting parameters. We chose the Urban Dynamometer Driving Schedule (UDDS) to estimate fuel consumption. Also, there are some constraints on engine torque $\left(T_{e}\right)$, motor torque $\left(T_{m}\right)$, generator torque $\left(T_{g}\right)$, engine speed $\left(\omega_{e}\right)$, motor speed $\left(\omega_{r}\right)$, generator speed $\left(\omega_{g}\right)$, and battery state of charge (SOC) that are defined as follows:

$$
\begin{gathered}
T_{\text {min-e }}<T_{e}<T_{\text {max }-e} \\
T_{\text {min-m }}<T_{m}<T_{\text {max }-m} \\
T_{\text {min-g }}<T_{g}<T_{\text {max-g }} \\
\omega_{\min -e}<\omega_{e}<\omega_{\text {max }-e} \\
\omega_{\min -r}<\omega_{r}<\omega_{\max -r} \\
\omega_{\min -g}<\omega_{g}<\omega_{\max -g} \\
S O C_{\min }<S O C<S O C_{\max }
\end{gathered}
$$

Identifying active constraints in each time step would be helpful to accelerate the calculation procedure. In this paper we used Hildreth quadratic programming procedure (42) that suggests an iterative approach to identify the active constraints in order to solve the problem.

Now we can investigate different possible control strategies, based on the trip information, by determining an appropriate reference SOC trajectory. This reference SOC is plugged into (1) and a constrained quadratic programming problem is solved for each case as follows.

\subsection{No knowledge of trip information (CDCS startegy)}

When there is no knowledge about the trip information, the best strategy is to use the vehicle full electric range at early stages of driving. Basically, in this control strategy the battery energy is used until the SOC reaches the reference level (charge depletion), so it is independent of the driving cycle and driving distance or any other information like initial SOC (9). Of course, the engine might be started in charge depletion mode at some points, where demanded power exceeds what motor and battery can provide. When the SOC drops to the lower limit, the strategy enters a loop governed by MPC. This controller tries to keep the state of charge around the reference and simultaneously minimize the fuel consumption (charge sustenance). Here, we assume the lower limit is equal to 0.3 because of battery parameters of health. It should be noted that CDCS strategy might be very useful to extend battery life cycle (13). 


\subsection{Known travelling distance (Blended mode strategy)}

In this case, we have knowledge of travelling distance to the next charging station. If travelling distance was less than vehicle all electric range, the best strategy would be going in pure electric mode. Otherwise, we follow another strategy. As mentioned earlier, it was shown that making a delay in charge sustaining stage would improve fuel economy. Therefore, we can assume the battery SOC is linearly decreased with the distance traveled by the vehicle according to the following relation (14):

$$
S O C_{\text {ref }}=\frac{S O C_{\text {high }}-S O C_{\text {low }}}{\text { Distance }_{\text {total }}} X+S O C_{\text {low }}
$$

where, $S O C_{\text {high }}, S O C_{\text {low }}$ and $X$ are initial battery state of charge, the lowest possible charge level of battery and distance traveled, respectively.

To implement this strategy, we have to plug the linear trajectory into the cost function, and MPC minimizes fuel consumption while making state of charge follow the reference.

\section{Control-oriented Model inside High-level Controller}

We need a simple and sufficiently accurate model inside the controller for making predictions. Instead of a high-fidelity chemistry-based battery model, we used a simple circuit model of the battery with a voltage source and an internal resistance (43).

$$
S \dot{O} C=-\frac{V_{o c}-\sqrt{V_{o c}^{2}-4\left(T_{m} \omega_{r} \eta_{m}^{-k}-T_{g} \omega_{g} \eta_{g}^{k}\right) R_{b a t t}}}{2 R_{b a t t} Q_{b a t t}}
$$

In this equation $V_{o c}, R_{b a t t}$, and $Q_{b a t t}$ are battery open circuit voltage, internal resistance, and capacity. $\eta_{m}$ and $\eta_{g}$ represent motor drive and generator drive efficiency respectively (including DC/DC convertor and DC/AC inverter) (44). In a power-split configuration, the engine, the electric motor and the generator are connected to each other by means of a planetary gear set. The motor and generator are connected to the ring and sun gears where the engine shaft is connected to the carrier. The ring gear is connected to the final drive which makes a gear ratio difference of $n_{F D}: 1$ between the power-split device and vehicle's driver wheels. By assuming $R$ and $S$ as the number of ring and sun gear teeth, we can write the kinematic relation for the power-split device:

$$
\omega_{r}+z \omega_{g}=(1+z) \omega_{e}
$$

where $z=S / R$.

The dynamics of powertrain is faster than any other dynamic of the whole system, and the loss power in planetary gear set is negligible. Therefore, the power balance and torque balance relation can be written as:

$$
\begin{aligned}
T_{f} \omega_{m}+T_{g} \omega_{g} & =T_{e} \omega_{e}+T_{m} \omega_{m} \\
T_{f}+T_{g} & =T_{e}+T_{m}
\end{aligned}
$$

where $T_{f}$ is the load as seen before the final drive.

By using (4) and (5), the relation between torques will be (45): 


$$
\begin{gathered}
z T_{e}=(1+z) T_{g} \\
T_{g}=z\left(T_{f}-T_{m}\right)
\end{gathered}
$$

The driver's demanded torque $\left(T_{d}\right)$ can be found as: $T_{d}=n_{F D} T_{f}$.

As a result, the engine torque and generator can be written in terms of $T_{m}$ and $T_{d}$ :

$$
\begin{gathered}
T_{e}=(1+z)\left(\frac{T_{d}}{n_{F D}}-T_{m}\right) \\
T_{g}=z\left(\frac{T_{d}}{n_{F D}}-T_{m}\right)
\end{gathered}
$$

In brief, the equation of controller model is:

$$
\begin{gathered}
S \dot{O} C=A \cdot S O C+B \cdot\left[\begin{array}{c}
T_{m} \\
\omega_{e}
\end{array}\right]+\tilde{B} \cdot\left[\begin{array}{c}
T_{d} \\
V \\
1
\end{array}\right] \\
y=C \cdot S O C+D \cdot\left[\begin{array}{c}
T_{m} \\
\omega_{e}
\end{array}\right]+\tilde{D} \cdot\left[\begin{array}{c}
T_{d} \\
V \\
1
\end{array}\right]
\end{gathered}
$$

This model will be discretized before plugging into the controller equations. $A, B, \tilde{B}, C, D$, and $\tilde{D}$ can be found after linearization at each sampling time around the operating point. The control inputs of system are motor torque $\left(T_{m}\right)$ and engine speed $\left(\omega_{e}\right)$. The only state is the battery $S O C$ and disturbances to this system are the driver's demanded torque (according to gas pedal) $\left(T_{d}\right)$ and vehicle velocity $(V)$ which can be found according to the driver model:

$$
a_{1} \frac{d V}{d t}+a_{2} V^{2}+a_{3}=T_{d}
$$

where $a_{1}=m R_{\text {tire }}, a_{2}=0.5 \cdot \rho \cdot A_{d} \cdot c_{d} \cdot R_{\text {tire }}$, and $a_{3}=f_{r} \cdot m . g \cdot R_{\text {tire }}$

The parameters $m, R_{t i r e}, \rho, A_{d}, c_{d}$, and $f_{r}$ are vehicle mass, tire radius, air density, vehicle frontal area, drag coefficient, and tire rolling resistance. Moreover, we use a receding horizon control principle where the actual control input to the plant only takes the first sample of the control input signal, while neglecting the rest of the trajectory. Also the fuel consumption map of the engine was estimated as:

$$
\dot{m}_{f}=\alpha \omega_{e}^{2}+\beta T_{e} \omega_{e}
$$

where $\alpha$ and $\beta$ are constants (46).

In the simulation procedure (Figure 1), the driver is responsible for following the predefined drive cycle with gas and brake pedal. Command from gas pedal is calibrated to give the demanded torque, which directly goes to control system and mechanical brake is a sort of standard PI controller. The demanded torque and the vehicle velocity, which is found through (9), are fed to the control system and the high-level controller calculates the control inputs every two seconds. Demanded torque, motor torque and speed, battery SOC and its variation are other information that the high level controller needs in order to predict proper controls for drivability, fuel economy and maintaining battery SOC around the predefined level. According to control inputs, new set points can be calculated for engine, motor and generator torque. Low-level controllers 


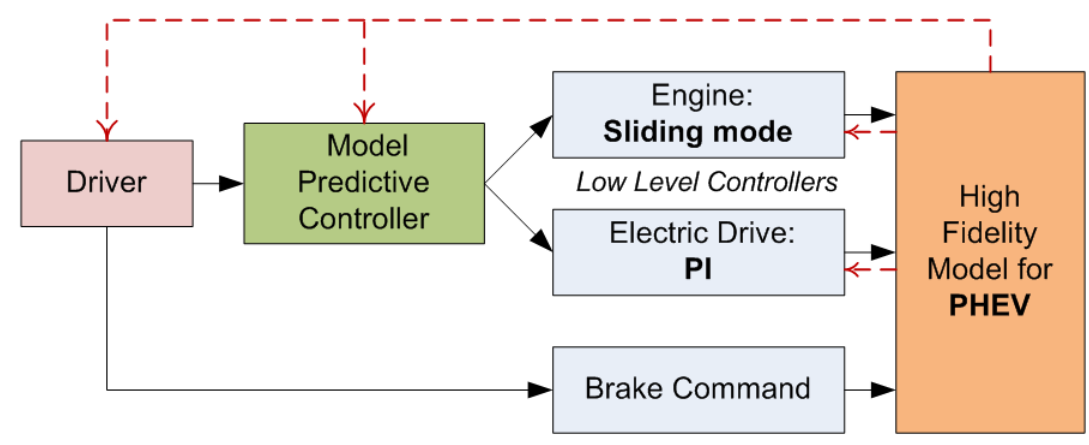

Fig. 1. Simulation procedure

are in charge of tracking these set points as closely as possible, as well as reducing emissions, as explained in the following section.

\section{Low-level Controller}

From the last section we have set points for engine torque, torque motor and generator speed. To make these sources follow the set points, we need to tune low-level controllers. For electric drives, a standard PI controller can be used. But for the engine a different approach is considered. Because of time-varying parameters and uncertainties associated with the internal combustion engine model, a robust model-based controller is preferable which can handle non-linearities. Since we are to apply the engine torque set point originated from MPC to a mean value gasoline engine model which captures some non-linear phenomena in the engine, we need an appropriate method for compensating probable uncertainties inside the engine model. Sliding mode control (SMC) is a reliable model-based control method for the engine torque management in practical cases, since it is capable of handling the model uncertainties. Here, we look at emissions control as well; the engine low-level controller should be capable of tracking the designated engine torque while minimizing engine emissions. The main control input is throttle angle. Other inputs, like injected fuel rate and ignition timing, highly affect the transient behaviour of the engine. According to legislation to have the best fuel economy and emission for the engine, we are not allowed to change these two parameters away from their optimum values for a long time (47). Therefore, throttle angle is generally more reliable and dominating engine input to change the steady state response in this case. But, we need to determine the amount of injected fuel as well to control air to fuel ratio which basically contributes to the engine emissions.

Engine torque management can be done in two ways: The first approach is using an engine torque sensor to measure crankshaft torque for feedback control. We consider the effects of the engine combustion torque, friction torque, pumping torque, and all accessory loads by following this approach. As mentioned before, spark timing and air to fuel ratio have effect on transient engine torque response. But, doing torque control based on these two parameters as the major inputs, makes them remain away from the optimal ranges. Thus, torque control in this way cannot guarantee low emissions, but it would reduce uncertainties especially in case of engine aging. The second approach is to measure and control manifold pressure, since the engine torque is a function of cylinder air flow which in turn is a function of the manifold pressure. Of course, air to fuel ratio is another parameter that determines the engine combustion torque. In case of assuming constant air to fuel ratio and ignition timing, the control goal can be changed to make the manifold pressure follow the desired value. If the throttle is used to control manifold pressure, the effect of ignition timing and air to fuel ratio on combustion torque does affect the throttle control. So the disadvantage of this second approach is a larger amount of calibration needed to find a proper conversion from desired torque to desired manifold pressure for all engine operating conditions. However, use of 
this strategy will not require a torque sensor (47). In this research, we use the second approach along with controlling the air to fuel ratio to get a desirable emission performance.

\subsection{Engine Control-oriented Model}

To reduce emissions, we focus on maximizing catalytic converter efficiency for different operating conditions of the engine. The conversion efficiencies are generally measured over a range of air to fuel ratios and catalytic converter body temperatures, requiring extensive data fitting and lookup tables. However, the conversion efficiency can be described by the S-shaped Wiebe function as proposed in (32):

$$
\eta_{\text {conv }}=\left(1-\exp \left\{-c_{1}\left(\frac{A F R-\lambda_{0}}{\Delta \lambda}\right)^{m_{1}}\right\}\right)\left(1-\exp \left\{c_{2}\left(\frac{T_{e x h}-T_{0}}{\Delta T}\right)^{m_{2}}\right\}\right)
$$

where $c_{1}, c_{2}, m_{1}, m_{2}, \lambda_{0}, \Delta \lambda, T_{0}$, and $\Delta T$ are constants that are determined by curve fitting to experimental data. $A F R$ and $T_{\text {cat }}$ stand for air to fuel ratio and catalytic converter body temperature.

For the engine torque control, we need a simplified model of a mean value engine as follows. In these equations, $P_{m}$, $\dot{m}_{a c t, f u e l}$, and $T_{e x h}$ are the state variables that define the manifold pressure, actual fuel rate, and exhaust temperature. The first dynamic equation is (12):

$$
\dot{P}_{m}=-\frac{\eta_{v} N_{c y l} V_{d} \omega_{e}}{60 N_{e n g} V_{m}} P_{m}+\frac{R T_{m a n}}{V_{m}}\left(C_{D} \cdot M A . P R I\right) A_{t h}
$$

where $A_{t h}$ is the throttle area and one of the control inputs. Throttle area can be found according to throttle angle $\theta$ and geometry ( $d_{t h}$ and $D_{t h}$ are diameter values for input and output vents and $\theta_{0}$ is the angle when throttle is totally closed):

$$
\begin{gathered}
A_{t h}=\frac{d_{t h} \cdot D_{t h}}{2}\left(-\sqrt{1-\left(\frac{d_{t h}}{D_{t h}}\right)^{2}}+\sqrt{1-\left(\frac{d_{t h} \cos \left(\theta_{0}\right)}{D_{t h} \cos (\theta)}\right)^{2}}\right) \\
+\frac{D_{t h}^{2}}{2}\left(\sin ^{-1}\left(\sqrt{1-\left(\frac{d_{t h}}{D_{t h}}\right)^{2}}\right)-\frac{\cos (\theta)}{\cos (\theta)} \sin ^{-1}\left(\sqrt{1-\left(\frac{d_{t h} \cos \left(\theta_{0}\right)}{D_{t h} \cos (\theta)}\right)^{2}}\right)\right)
\end{gathered}
$$

Moreover $\eta_{v}$ is the volumetric efficiency and a function of manifold pressure and engine speed $\left(\omega_{e}\right), N_{c y l}$ is the number of cylinders that is 4 here, $V_{d}$ and $V_{m}$ are the engine displacement and air manifold volume respectively, $N_{e n g}$ is 2 for four stroke engine, $R$ is air constant, $T_{\operatorname{man}}$ is the manifold temperature (considered constant for simplicity), $C_{D}$ is the throttle discharge coefficient, $M A=\frac{P_{0}}{\sqrt{R T_{0}}}$ where $P_{0}$ and $T_{0}$ are atmosphere pressure and temperature, $P R I$ is a non-dimensional value to consider sub and supersonic air flow which depends on air heat capacity, manifold and atmosphere pressure.

The air mass rate entering the cylinders can be found as:

$$
\dot{m}_{\text {air }}=\frac{\eta_{v} N_{c y l} V_{d} \omega_{e}}{60 N_{e n g} V_{m}} P_{m}
$$

To estimate the combustion torque, we need to know how much fuel goes into the engine. In fact, all amount of injected fuel cannot get into the cylinders because of vaporization. To consider this, we use another dynamic equation for wall-wetting effect (16):

$$
\ddot{m}_{a c t, f u e l}=\frac{1}{\tau_{f}}\left(-\dot{m}_{a c t, f u e l}+\dot{m}_{i n j, f u e l}\right)
$$

where $\tau_{f}$ is a constant and $\dot{m}_{a c t, f u e l}$ is the actual amount of fuel rate that is burnt inside the engine to generate power. The injected amount of fuel $\left(\dot{m}_{i n j, f u e l}\right)$ is another control input in our problem. Now, the engine generated torque can be estimated via: 


$$
T_{\text {ind }}=\frac{\dot{m}_{a c t, f u e l} \cdot H_{f} \cdot \eta_{\Delta} \cdot \eta_{A F R} \cdot \eta_{i}}{\omega_{e}}
$$

where $\eta_{i}$ and $H_{f}$ are engine thermal efficiency (approximately a function of engine speed and manifold pressure) and gasoline heat of combustion respectively. Readers are referred to (48) for table of numeric parameters used in this engine model. Figure 2 shows the air to fuel ratio and ignition timing efficiencies $\left(\eta_{A F R}\right.$ and $\left.\eta_{\Delta}\right)$.

Air to fuel ratio can be described as:

$$
A F R=\frac{\dot{m}_{a i r}}{\dot{m}_{\text {act }, \text { fuel }}}
$$

According to (49) we can write the third dynamic equation to estimate the exhaust gas temperature.

$$
\dot{T}_{e x h}=\frac{\omega_{e}}{2 \pi}\left[-T_{e x h}+S T \cdot A F I\right]
$$

where $A F I=\cos (0.13(A F R-13.5)), S T=7.5 \Delta+600$ and $\Delta$ is the angle of crankshaft the ignition occurs.

Here, it is assumed that the catalytic converter body temperature is proportional to exhaust temperature (50).

\subsection{Engine Controls Design}

In order to control the engine torque and catalytic converter efficiency, three different sliding surfaces are defined: $S_{1}, S_{2}$, and $S_{3}$ for torque, air to fuel ratio, and exhaust temperature control.

Let $S_{1}=T_{\text {ind }}-T_{\text {des }}$, where $T_{\text {des }}$ is the reference engine torque determined by the high-level controller. By taking the derivative of $S_{1}$ we have:

$$
\dot{S}_{1}=\dot{T}_{i n d}-\dot{T}_{\text {des }}=\frac{\eta_{v} \cdot N_{c y l} \cdot V_{d} \cdot H_{f} \cdot \eta_{\Delta} \cdot \eta_{A F R} \cdot \eta_{i}}{60 N_{\text {eng }} \cdot R T_{m}} \cdot \frac{P_{m}}{A F R}-\dot{T}_{d e s}
$$

By using (16) and rearranging the terms of (19) we can find the control input for the first sliding surface:

$$
\begin{gathered}
A_{t h}=\frac{V_{m}}{R \cdot T_{m} \cdot C_{D} \cdot M A \cdot P R I}\left[\frac{60 N_{e n g} \cdot R T_{m}}{\eta_{v} \cdot N_{c y l} \cdot V_{d} \cdot H_{f} \cdot \eta_{\Delta} \cdot \eta_{A F R} \cdot \eta_{i}}\left(\dot{S}_{1}+\dot{T}_{d e s}\right) \cdot A F R\right. \\
\left.+\left(\frac{\eta_{v} N_{c y l} V_{d} \omega_{e}}{60 N_{e n g} V_{m}}+\frac{A \dot{F} R}{A F R} P_{m}\right)\right]
\end{gathered}
$$

For the second sliding surface, we assume $S_{2}=A F R-A F R_{\text {des }}$. $A F R_{\text {des }}$ is the desired air to fuel ratio value. By differentiating $S_{2}$ and taking time derivative of AFR, we can write:

$$
\dot{S}_{2}=A \dot{F} R-A \dot{F} R_{d i s}=\frac{\ddot{m}_{a i r}-A F R . \ddot{m}_{a c t, f u e l}}{\dot{m}_{a c t, f u e l}}
$$

By using (15) and (21) we can find injected fuel rate as another manipulated input:

$$
\dot{m}_{i n j, f u e l}=\frac{\tau_{f}}{A F R}\left\{\ddot{m}_{a i r}-\dot{m}_{a c t, f u e l}\left(\dot{S}_{2}+A \dot{F} R_{d e s}\right)\right\}+\dot{m}_{a c t, f u e l}
$$

The desired air to fuel ratio is constant (stoichiometry) so $A \dot{F} R_{d e s}=0$.

The last sliding surface belongs to the exhaust temperature control. By taking time derivative of $S_{3}=T_{\text {exh }}-T_{\text {exh,des }}$ and (18), we can find appropriate ignition timing as the third control input. 


$$
\Delta=\frac{1}{7.5}\left[\frac{T_{e x h}+\left(2 \pi / \omega_{e}\right)\left(\dot{S}_{3}+\dot{T}_{e x h, d i s}\right)}{\cos (0.13(A F R-13.5))}-600\right]
$$

Where $T_{e x h, d e s}$ is the desired exhaust gas temperature. Of course, the exhaust temperature shouldn't be too high to damage the catalytic converter.

Now, we can design $\dot{S}_{1}, \dot{S}_{2}$ and $\dot{S}_{3}$ to satisfy reachability condition and find an acceptable torque and emissions generation for the engine, accordingly. The sliding surfaces are chosen as:

$$
\begin{gathered}
\dot{S}_{1}=-K_{1} \operatorname{sat}\left(\frac{S_{1}}{\phi_{1}}\right) \\
\dot{S}_{2}=-K_{2} \operatorname{sat}\left(\frac{S_{2}}{\phi_{2}}\right) \\
\dot{S}_{3}=-K_{3} S_{3}
\end{gathered}
$$

Where saturation function is defined as:

$$
\operatorname{sat}\left(\frac{S}{\phi}\right)= \begin{cases}1 & \frac{S}{\phi}>1 \\ \frac{S}{\phi} & \left|\frac{S}{\phi}\right| \leq 1 \\ -1 & \frac{S}{\phi}<-1\end{cases}
$$

The saturation function imposes linear control in a boundary layer of width $\phi$. This will reduce the undesirable chattering effect at the price of slower response of the system as compared to using a signum function.

Indeed, the two first sliding surfaces are coupled and makes it more difficult to control the engine torque and AFR separately. Also, ignition timing and AFR changing can deteriorate engine torque performance (according to (16)). However, using appropriate values for $K_{1}, K_{2}, K_{3}, \phi_{1}$, and $\phi_{2}$ will result in a good performance for the controller.

\section{PHEV High-fidelity Model in MapleSim}

The simulation model is built in MapleSim 5 which is an environment for multi-domain system simulation with direct access to system equations to make it more convenient for model reduction and optimization purposes. This model consists of 5 main parts for power-split architecture: battery, electric drive, internal combustion engine, driveline and vehicle dynamics. A schematic of the whole simulation model is demonstrated in Figure 3. This model is cross-validated with the experimental database available in the Autonomie software which is developed by Argonne National laboratory in order to make it close to the real system (51).

\subsection{Li-ion Battery}

The battery is the most important part in a plug-in hybrid powertrain, since it determines how far the vehicle can go in full electric mode. Unfortunately, most simulations for hybrid electric vehicles are conducted according to a simple circuit model of the battery. Here, the model of the battery is chemistry-based and most features of a Lithium-ion battery including thermal issues are considered. Generally, the problem with solving battery equations is the numerical issues due to exponential terms and combination of both very large and very small parameters. Therefore, the battery is modeled by the linear graph method. The linear graph model simulates faster compared to the original lumped parameter model. In this model of the battery that contains 38 parameters, 4 differential equations and 18 algebraic equations should be solved for each cell (52). This model will give us a better view of electrochemical processes inside an actual lithium-ion battery pack. 


\subsection{Electric Drive}

The electric drive model consists of 4 parts: motor (so called MG-2 for Toyota Prius), generator (MG-1), and two power converters (without switching effect) for each of these two machines.

\subsection{Mean Value Engine}

The mean value engine model consists of 5 parts: engine control unit (ECU), throttle body, intake/exhaust manifold, combustion chamber and catalyst body. We use the ECU to program the low-level controller which is designed based on a sliding mode control approach. The throttle body receives the throttle angle command and changes it to the air flow entering the intake manifold. In fact, all air that passes the throttle cannot enter the combustion chamber. This amount of air depends on intake manifold pressure and engine speed for naturally aspirated engines like what we have here. This effect is referred to as engine volumetric efficiency. In the combustion chamber, the power generated is calculated according to the air to fuel ratio, mechanical, and thermal losses.

\subsection{Driveline}

The driveline connects the motor (ring gear), generator (sun gear) and mean value engine (carrier) via a power-split device. The ring gear shaft is connected to the final drive with appropriate gear ratios.

\subsection{Vehicle Model}

The vehicle model has 14 DOF, including 6 DOF for the chassis. The suspension displacement on each wheel and wheel spins add 8 DOF to the model. Moreover, this vehicle is capable of being steered. Tires on this vehicle are modeled according to the magic formula by Pacejka. Although, the longitudinal dynamics of the vehicle is the most important one for assessing fuel consumption, we connect the hybrid powertrain final drive to the wheels of this vehicle model to make the simulation represent the full 3D vehicle motion and cover different maneuvers possible in the UDDS cycle.

\section{Results of Simulation}

To evaluate the performance of the designed controls, the model-in-the-loop (MIL) simulation is conducted by using the aforementioned high-fidelity model. Therefore, the high-fidelity in MapleSim is converted to an S-function and the designed control package is applied to the S-function inside Matlab/Simulink environment.

\subsection{Without Emissions Control}

Figure 4(a) shows, the vehicle follows two successive UDDS cycles for the blended mode strategy without controlling the emissions. As seen, the battery state of charge drops to the minimum possible level at the end of the trip. Indeed, if the horizontal axis is replaced with the travelled distance, the depletion trajectory will be a near linear profile. Therefore, the high-level controller has maintained drivability and also kept the final SOC above the minimum level. Figure 4(b) and 4(c) show that the low-level controllers have made the engine and MG-2 torque follow the MPC-prescribed trajectory. According to figure 4(d), the resulting fuel consumption is $331.2 \mathrm{~g}$.

Figure 5(a) demonstrates the drivability of vehicle in charge depletion/ charge sustenance mode, where the vehicle goes in pure electric mode at the beginning of its trip. When the battery state of charge dropped to $S O C_{r e f}=0.3$ at $t=1714 \mathrm{~s}$, the engine kicks in and maintains the $S O C$ around $S O C_{r e f}$. Figure 5(b) shows that the vehicle is propelled only by MG-2 up to $15.83 \mathrm{~km}$. In this part of the trip the engine is off (Figure 5(c)). This strategy results in higher fuel consumption of $366.4 g$ in comparison to the blended mode strategy, according to Figure 5(d). 
Table 1. Fuel consumption comparison

\begin{tabular}{llll}
\hline Strategy & consumption increase & Fuel consumption & in $1 / 100 \mathrm{~km}(\mathrm{MPG})$ \\
\cline { 2 - 4 } & by e-control $(\%)$ & w/O e-control & we-control \\
\hline CDCS & 12.02 & $1.83(129)$ & $2.05(115)$ \\
Blended mode & 13.86 & $1.66(142)$ & $1.89(124)$ \\
\hline
\end{tabular}

e-control=emissions control, w=with, w/o=without

\subsection{With Emissions Control}

Figure 6(a) shows the drivability of the vehicle in the blended mode while controlling the engine emissions. Figure 6(b) shows more frequent operation of MG-2 in comparison to the case the engine emission is not controlled (Figure 4(b)). The reason is the failure of the engine to provide adequate torque to propel the vehicle for all time steps. This failure is due to the extra heat loss occurs inside the engine. As mentioned before, one way to have less emissions is to keep the catalyst temperature high. To reach this goal, we need to increase the temperature of the gas inside the exhaust manifold. Changing the ignition timing makes it possible to have more heat loss and definitely exhaust gas with higher temperature at the expense of higher fuel consumption. In brief, to warm up the catalyst, a larger amount of the combustion energy should be dissipated as heat instead of producing mechanical energy inside the engine. Figure 6(c) shows the SMC and PI controllers are successful in making the engine and MG-2 follow the MPC-prescribed trajectories. Changing ignition timing and AFR results in a decrease of engine combustion torque which is shown by corresponding efficiencies in equation (16). Therefore, Figure 6(d) indicates more fuel consumption of $377.8 \mathrm{~g}$.

Figure 7 shows the results for the CDCS strategy. Here, the fuel consumption has risen to $407.8 \mathrm{~g}$.

As mentioned earlier, exhaust temperature is closely related to catalytic converter body temperature that contributes to conversion efficiency. Ignition timing has a considerable effect on determining exhaust temperature. Figure 8(a) shows ignition timing throughout the vehicle travel time. For maintaining combustion stability, we confine the ignition timing within $\Delta \in[0,20]$. As a result, exhaust temperature $\left(T_{e x h}\right)$ remains high enough for the whole trip.

Figure 8(b) shows the manifold pressure to compare ignition timing and AFR versus throttle angle for different time steps. Figure 8(c) shows AFR which is determined by the second level of sliding mode control. As seen, AFR is alternating around the stoichiometry ratio and is confined within an acceptable range. Figure 8(d)shows the conversion efficiency that mostly remains on its maximum level.

Figure 9 demonstrates the controls and variables related to the engine emission control in the CDCS strategy. It is evident that the engine emission is zero for the full electric mode of driving.

The fuel consumption results are summarized in Table 1. Since the MIL simulation is conducted by using the validated high-fidelity powertrain model, we are expecting similar results by performing hardware-in-the-loop simulation as a future work. Moreover, the readers are referred to (53), where the performance of the current high-level controls is compared to the adaptive ECMS power management system.

Figure 10 demonstrates the engine operating points for CDCS and blended mode strategies along two UDDS cycles. It is obvious that the operating points are accumulated around the engine optimum operating curve since the fuel minimization term is considered inside the cost function (1).

Figure 11 shows the distribution of catalyst operating point for two mentioned strategies.

In (54), the authors have simulated a PHEV powertrain with power-split architecture using a forward vehicle simulation model.They have reported 90 MPG along UDDS cycle which translates to $2.61 \mathrm{l} / 100 \mathrm{~km}$ fuel economy. As mentioned earlier, MPC power management system leads to at least 115 MPG fuel economy by considering emissions control which increases the fuel consumption. As a result, we have improved fuel economy by $27 \%$ to $58 \%$ depending on the battery depletion trajectory. It is noteworthy that by controlling the air to fuel ratio around the stoichiometric value, there is a good 
balance in conversion efficiency for all major pollutant species $C O, N O x$, and $H C$ (55). Indeed, the main objective of the supervisory controller which is reducing fuel consumption helps reducing $C O$, and $H C$ further. The simulation results show that the main objectives of the whole control scheme in order to reduce the vehicle environmental footprint has been accomplished.

\section{Conclusion}

In this paper, we designed a power management scheme including high-level and low-level controllers to reduce fuel consumption and engine emissions of a power-split plug-in hybrid electric vehicle. The validated high-level controller was designed using a model predictive control approach. To design a low-level controller for the gasoline engine, we used sliding mode control to make the engine have a desirable torque and emissions performance. The control package was applied to a high fidelity model of the vehicle, including a chemistry-based model of the Lithium-ion battery developed in MapleSim 5, to get more realistic results. The simulation was done for both charge depletion / charge sustenance and blended mode strategies. The results showed a promising fuel consumption of $1.89 \mathrm{l} / 100 \mathrm{~km}$ and $2.05 \mathrm{l} / 100 \mathrm{~km}$ for the blended mode and CDCS strategies respectively, while the engine emissions were controlled during the vehicle travel time in the UDDS cycle.

Acknowledgement- The authors gratefully acknowledge the NSERC/Toyota/Maplesoft Industrial Research Chair program for financial support of this research.

\section{References}

[1] Ehsani M, Gao Y, Emadi A. Modern Electric, Hybrid Electic and Fuel Cell Vehicles: Fundamentals, Theory, and Design. 3rd ed. Taylor and Francis Group LLC; 2010.

[2] Wang N, Gong Z, Ma J, Zhao J. Consumer total ownership cost model of plug-in hybrid vehicle in China. Proc Inst Mech Eng, Part D (J Automob Eng). 2012;226(5):591 âŁ“ 602.

[3] Markel T. Plug-in HEV Vehicle Design Options and Expectations. ZEV Technology Symposium, California Air Resources Board, Sacramento, CA, USA. 2006;.

[4] Muta K, Yamazaki M, Tokieda J. Development of New-generation Hybrid System THS II Drastic Improvement of Power Performance and Fuel Economy. SAE Technical Paper. 2004;p. No.2004-01-0064.

[5] Wirasingha S, Emadi A. Classification and Review of Control Strategies for Plug-in Hybrid Electric Vehicles. IEEE Transactions on Vehicular Technology;60(1):111 - 122.

[6] Powell BK, Bailey KE, Cikanek SR. Dynamic Modeling and Control of Hybrid Electric Vehicle Powertrain Systems. Electric Vehicle Symposium. 2007;p. 17 â€“ 33.

[7] Rousseau A, Pagerit S, Gao D. Plug-in Hybrid Electric Vehicle Control Strategy Parameter Optimization. Electric Vehicle Symposium. 2006;.

[8] Vahidi A, Stefanopoulou A, Peng H. Current Management in a Hybrid Fuel Cell Power System: A Model Predictive Control Approach. IEEE Trans Control Syst Technol. 2006;14(6):1047 - 1057.

[9] Marano V, Tulpule P, Stockar S, Onori S, Rizzoni G. Comparative Study of Different Control Strategies for Plug-in Hybrid Electric Vehicles. SAE World Congress and Exhibition Detroit MI USA. 2004;

[10] Moura FHKCDSSJL S J. A Stochastic Optimal Control Approach for Power Management in Plug-in Hybrid Electric Vehicles. IEEE Transactions on Control Systems Technologies. 2011;19(3):545 - 555.

[11] O’Keefe M, Markel T. Dynamic Programming Applied to Investigate Energy Management Strategies for a Plug-in HEV. 22nd International Battery, Hybrid and Fuel Cell Electric Vehicle Symposium, (EVS-22). 2010;

[12] Zhang C, Vahidi A. Real-time Optimal Control of Plug-in Hybrid Vehicles with Trip Preview. American Control Conference;p. 6917 6922. 
[13] Moura SJ, Stein JL, Fathy HK. Battery Health-consious Power Management for Plug-in Hybrid Vehicles via Stochastic Control. IEEE Transactions on Control Systems Technology. 2010;21(3):679 - 694.

[14] Zhang C, Vahidi A, Li X, Essenmacher D. Role of Trip Information Preview in Fuel Economy of Plug-in Hybrid Vehicles. ASME Dynamic Systems and Control Conference;.

[15] Gong Q, Li Y, Peng Z. Trip Based Optimal Power Management of Plug-in Hybrid Electric Vehicles Using Gas-kinetic Traffic Flow Model. American Control Conference. 2008;p. 3225 âE“ 3230.

[16] Gong Q, Li Y, Peng Z. Trip-based Optimal Power Management of Plug-in Hybrid Electric Vehicles. IEEE Transactions on Vehicular Technology. 2008;57(6):3393-3401.

[17] Vajedi M, Taghavipour A, Azad NL. Traction Motor Power Ratio and Speed Trajectory Optimization for Power Split PHEVs Using Route Information. International Mechanical Engineering Congress and Exposition, ASME 2012. 2012;.

[18] Alessio A, Bemporad A. A Survey on Explicit Model Predictive Control. Lecture Notes in Control and Information Sciences;384:345 369.

[19] Di Cairano S, Yanakiev D, Bemporad A, Kolmanovsky I, Hrovat D. An MPC Design Fow for Automotive Control and Applications to Idle Speed Regulation. Proc 47th IEEE Conf on Dec and Control;p. 5686 âE“ 5691.

[20] Di Cairano S, Tseng H. Driver-assist Steering by Active Front Steering and Differential Braking: Design, Implementation and Experimental Evaluation of a Switched Model Predictive Control Approach. Proc 49th IEEE Conf on Dec and Control;p. 2886 âŁ“ 2891.

[21] Falcone P, Borrelli F, Asgari J, Tseng H, D H. Predictive Active Steering Control for Autonomous Vehicle Systems. IEEE Transactions on Control Systems Technology;15(3):566 âE“ 580.

[22] Garcia C, Prett D, Morari M. Model Predictive Control: Theory and PracticeâŁ“a survey. Automatica;25(3):335 - 348.

[23] Wang Z. Model Predictive Control for Hybrid Electric Vehicle [PhD dissertation]. The Chinese University of Hong Kong; 2008.

[24] Borhan H, Vahidi A, Phillips A, Kuang M, Kolmanovsky I. Predictive Energy Management of a Power-split Hybrid Electric Vehicle. American Control Conference. 2009;p. 3970-3976.

[25] Taghavipour A, Azad NL, , McPhee J. An Optimal Power Management Strategy for Power Split Plug-in Hybrid Electric Vehicles. International Journal of Vehicle Design. 2012;60(3):286 - 304.

[26] Smith D, Lohse-Busch H, Irick D. A Preliminary Investigation into the Mitigation of Plug-in Hybrid Electric Vehicle Tailpipe Emissions Through Supervisory Control Methods. SAE Technical Paper. 2010;p. No.2010-01-1266.

[27] Kum D, Peng H, Bucknor NK. Optimal Catalyst Temperature Management of Plug-in Hybrid Electric Vehicles. American Control Conference. 2011;p. $2732-2738$.

[28] Tian Y, Sun W, Qu D, Wang L. Study of a Exhaust After-Treatment System Applied to Hybrid Vehicle. Asia-Pacific Power and Energy Engineering Conference (APPEEC). 2010;p. 1 - 4.

[29] Chan SH, Hoang DL, Zhou PL. Heat Transfer and Chemical Kinetics in the Exhaust System of a Cold-Start Engine Fitted With a Three Way Catalytic Converter. Proc Inst Mech Eng, Part D (J Automob Eng). 2000;214(7):765 âE“ 777.

[30] Wurzenberger JC, Auzinger G, Heinzle R, Wanker R. 1D Modeling of Reactive Fluid Dynamics, Cold Start Behavior of Exhaust Systems. SAE Technical Paper;p. No.2006-01-1544.

[31] Souder JS, Hedrick JK. Adaptive Sliding Mode Control of AirâŁ “Fuel Ratio in Internal Combustion Engines. International Journal of Robust and Nonlinear Control. 2011;14(6):525 - 541.

[32] Shaw B, Fischer GD, Hedrick JK. A Simplified Coldstart Catalyst Thermal Model to Reduce Hydrocarbon Emissions. Proceedings of 15th Triennial World Congress of the International Federation of Automatic Control. 2002;p. 1915 - 1921.

[33] Ceraolo M, di Donato A, Franceschi G. A General Approach to Energy Optimization of Hybrid Electric Vehicles. IEEE Transaction on Vehicular Technology. 2008;57(3):1433 - 1441.

[34] Lin CC, Peng H, Grizzle JW, Kang JM. Power Management Strategy for a Parallel Hybrid Electric Truck. IEEE Trans Control Syst Technol. 2003;11(6):839 âE“ 849 .

[35] Kolmanovsky I, Nieuwstadt M, Sun J. Optimization of Complex Powertrain Systems for Fuel Economy and Emissions. IEEE International 
Conference on Control Applications, HI. 1999;p. 833 - 839.

[36] Lukic SM, Emadi A. Emissions and Fuel Economy Trade-Off for Hybrid Vehicles Using Fuzzy Logic. Math Comput Simul. 2004;66(2):155 âŁ“" 172.

[37] Kum D, Peng H, Bucknor NK. Supervisory Control of Parallel Hybrid Electric Vehicles for Fuel and Emission Reduction. Journal of Dynamic Systems, Measurement, and Control. 2011;133(6):833 - 839.

[38] Dorri M, Shamekhi A. Design of an Optimal Control Strategy in a Parallel Hybrid Vehicle in Order to Simultaneously Reduce Fuel Consumption and Emissions. SAE Technical Paper. 2011;p. No.2011-01-0894.

[39] Sagha H, Farhangi S, Asaei B. Modeling and Design of a NOx Emission Reduction Strategy for Lightweight Hybrid Electric Vehicles. 35th Annual Conference of IEEE Industrial Electronics,(IECON '09). 2009;p. 334 - 339.

[40] Gao Z, Kim M, Choi J, Daw CS, Parks II JE, Smith DE. Cold-start emissions control in hybrid vehicles equipped with a passive adsorber for hydrocarbons and nitrogen oxides. Proc Inst Mech Eng, Part D (J Automob Eng). 2012;226(10):1396 âŁ“ 1407.

[41] Taghavipour A, Vajedi M, Azad NL, McPhee J. Predictive Power Management Strategy for a PHEV Based on Different Levels of Trip Information. IFAC Workshop on Engine and Powertrain Control, Simulation and Modeling (E-COSM'12). 2012 ;p. 326 - 333.

[42] Wang L. Model Predictive Control System Design and Implementation Using Matlab. Springer; 2009.

[43] Liu J, Peng H, Filipi Z. Modeling and Analysis of the Toyota Hybrid System. International Conference on Advanced Intelligent Mechatronics. 2005;p. $134-139$.

[44] Liu J. Modeling, Configuration and Control Optimization of Power Split Hybrid Vehicles [PhD dissertation]. University of Michigan. Ann Arbor (MI); 2007.

[45] Guzzella L, Sciarretta A. Vehicle Propulsion Systems: Introduction to Modeling and Optimization. 2nd ed. Springer; 2007.

[46] Nicholas K, Hedrick K, Borrelli F. Integrating Traffic Data and Model Predictive Control to Improve Fuel Economy. IFAC Symposium on Control in Transportation Systems. 2009;p. 155 - 160.

[47] Lamberson DM. Torque Management of Gasoline Engines [MSc dissertation]. University of California at Berkeley. Berkeley (CA); 2003.

[48] Saeedi M. A Mean Value Internal Combustion Engine Model in MapleSim [MSc dissertation]. University of Waterloo. Waterloo (ON); 2010.

[49] Sanketi PR, Zavala JC, Hedrick JK. Dynamic Surface Control of Engine Exhaust Hydrocarbons and Catalyst Temperature for Reduced Cold Start Emissions. Proc of International Federation of Automatic Control (IFAC) Conference. 2005;.

[50] Zavala JC. Engine Modeling and Control for Minimization of Hydrocarbon Coldstart Emissions in SI Engines [PhD dissertation]. University of California, Berkeley. Berkeley (CA); 2007.

[51] Taghavipour A, Masoudi R, Azad NL, McPhee J. High-fidelity Modeling of a Power-split Plug-in Hybrid Electric Powertrain for Control Performance Evaluation. ASME 15th International Conference on Advanced Vehicle Technologies (AVT). 2013;.

[52] Dao TS, McPhee J. Dynamic Modeling of Electrochemical Systems Using Linear Graph Theory. Journal of Power Sources. 2011;196(23):10442 - 10454.

[53] Vajedi M, Taghavipour A, Azad NL, McPhee J. A Comparative Analysis of Route-Based Power Management Strategies for Real-Time Application in Plug-In Hybrid Electric Vehicles. American Control Conference. 2014;

[54] Rahman SA, Zhang N, Zhu J. A Comparison on Fuel Economy and Emissions for Conventional Hybrid Electric Vehicles and The UTS Plug-in Hybrid Electric Vehicle. The 2nd International Conference on Computer and Automation Engineering (ICCAE). 2010 ;p. 20 -25 .

[55] Guzzella L, Onder C. Introduction to Modeling and Control of Internal Combustion Engine Systems. 2nd ed. Springer; 2010. 
(a)

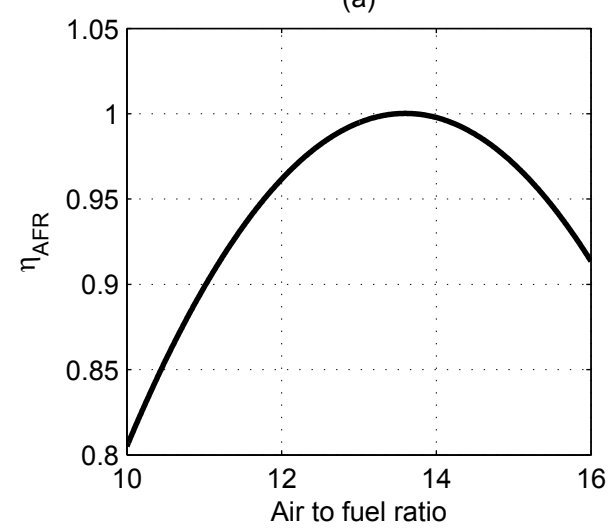

(b)

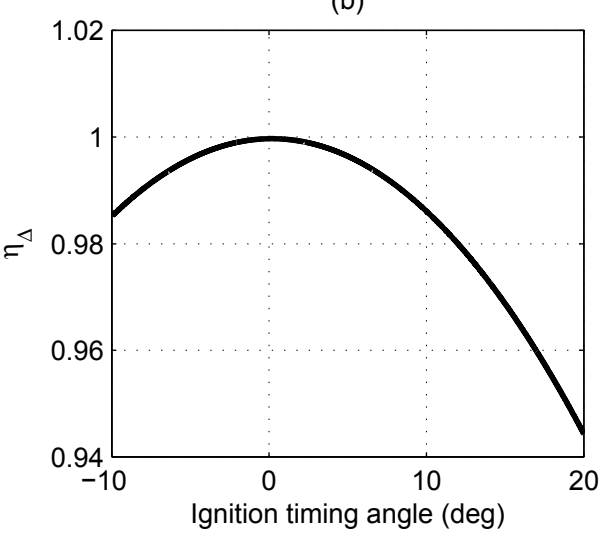

Fig. 2. Engine torque change with air to fuel ratio and ignition timing

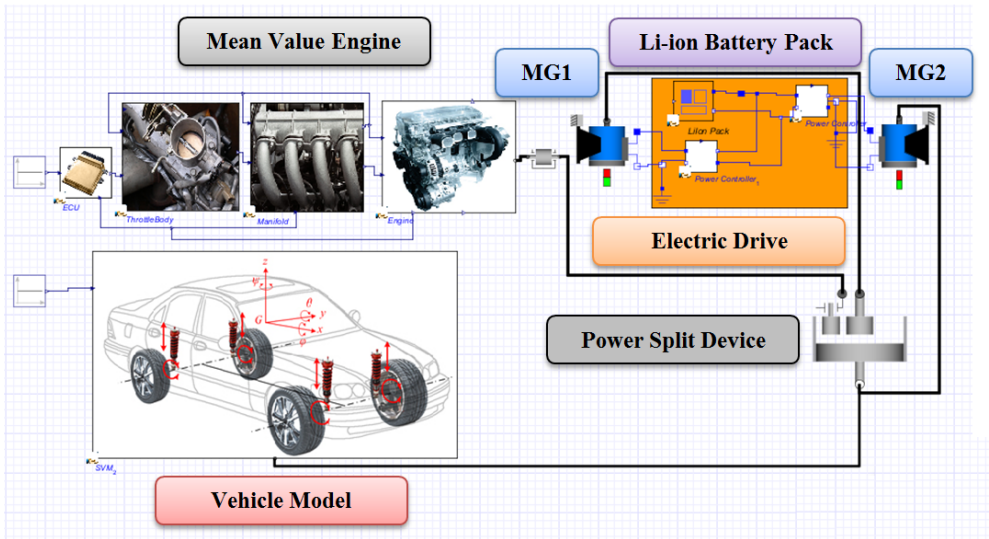

Fig. 3. PHEV high-fidelity model in MapleSim 
(a) Blended Mode Strategy without Emission Control

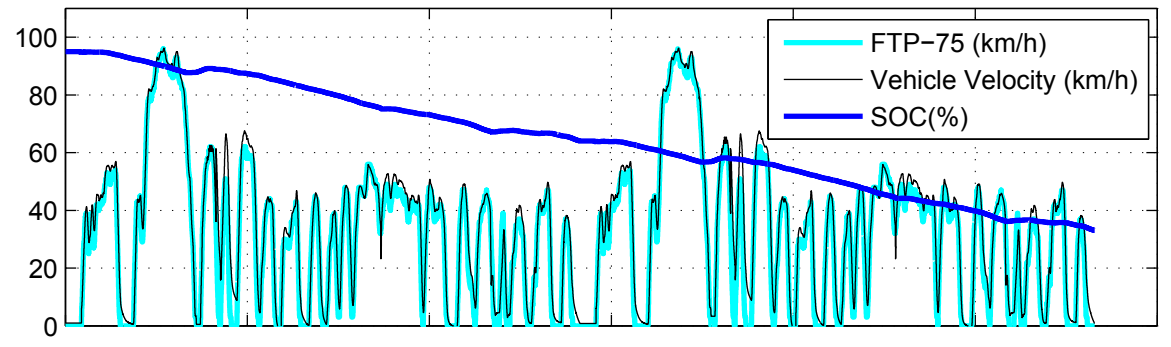

(b) MG2 Torque $(\mathrm{Nm})$

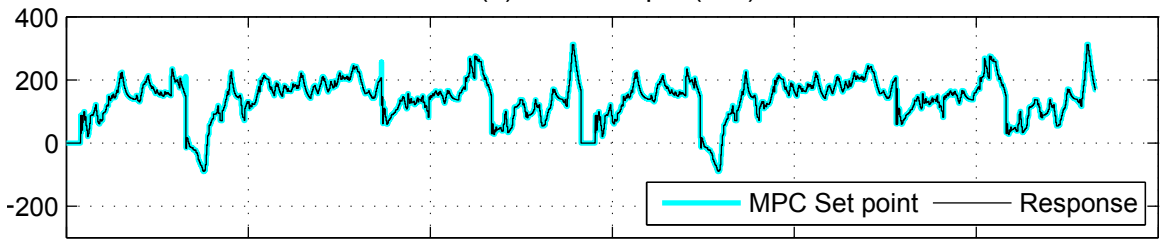

(c) Engine Torque (Nm)

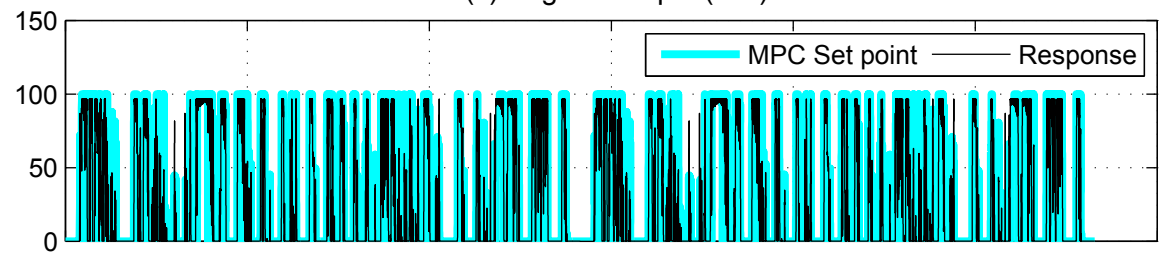

(d) Fuel Consumption (g)

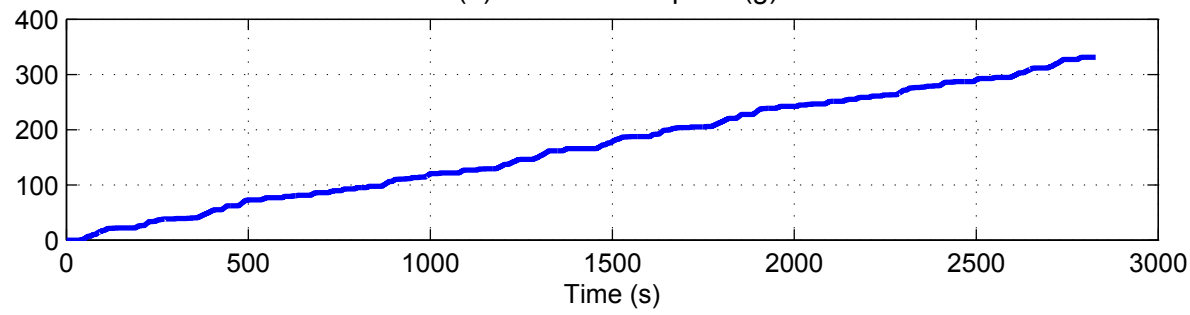

Fig. 4. Blended mode strategy without emissions control: (a) Velocity and battery SOC (b) MG-2 torque (c) Engine torque (d) Fuel consumption 
(a) CDCS Strategy without Emission Control

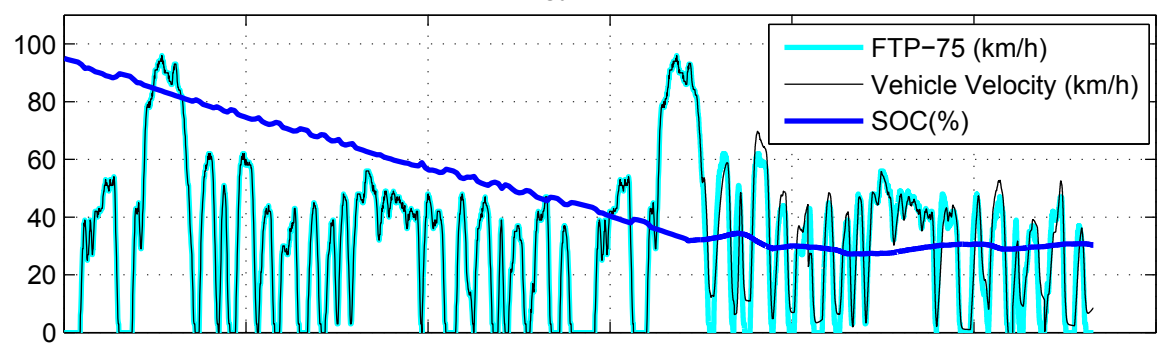

(b) MG2 Torque (Nm)

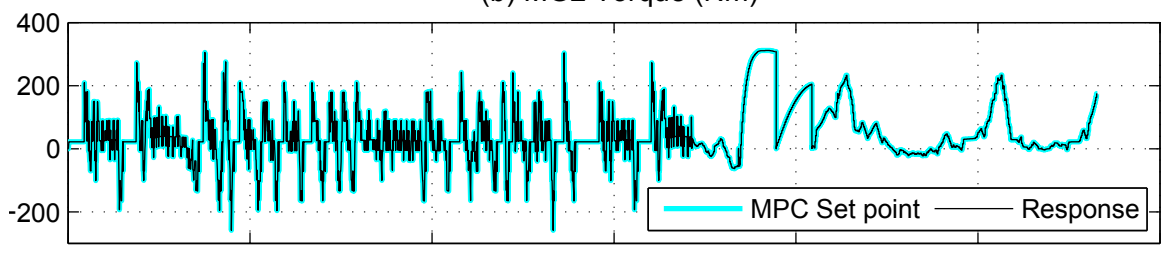

(c) Engine Torque (Nm)

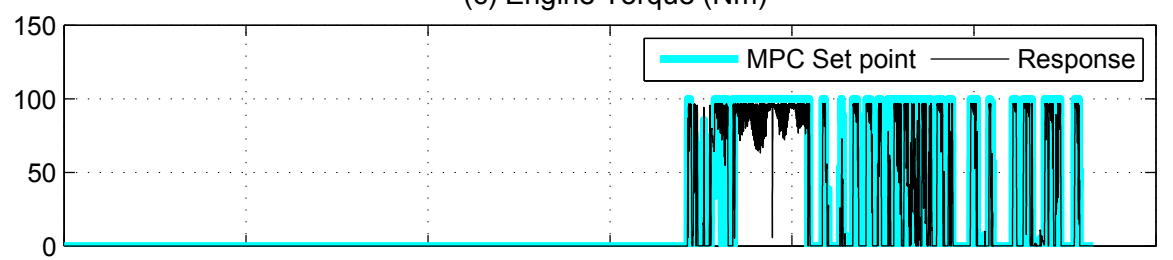

(d) Fuel Consumption (g)

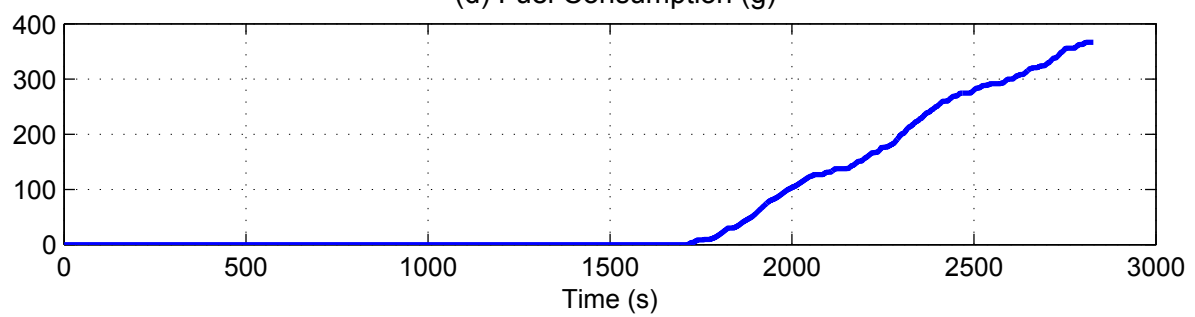

Fig. 5. CDCS strategy without emissions control: (a) Velocity and battery SOC (b) MG-2 torque (c) Engine torque (d) Fuel consumption 
(a) Blended Mode Strategy with Emission Control

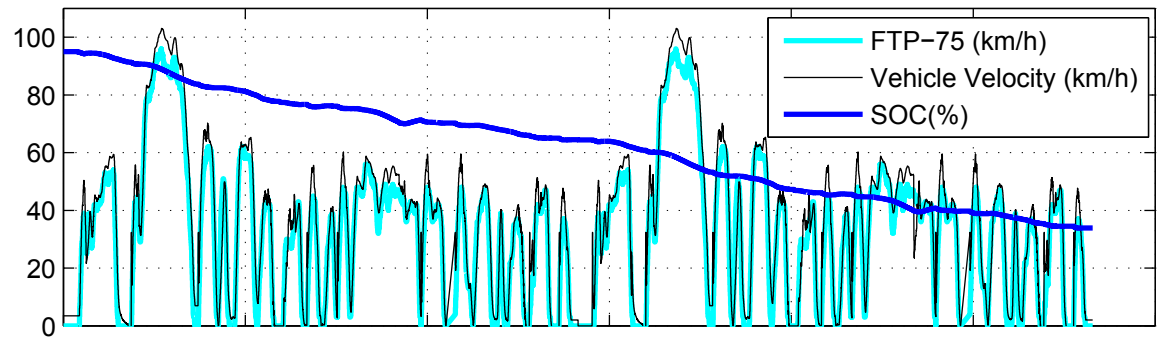

(b) MG2 Torque (Nm)

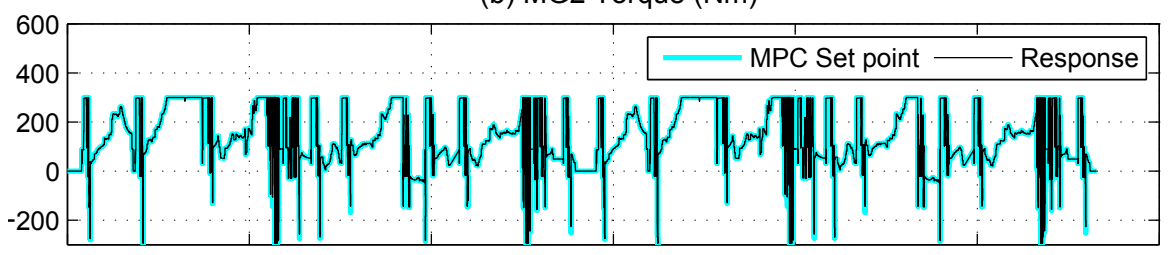

(c) Engine Torque (Nm)

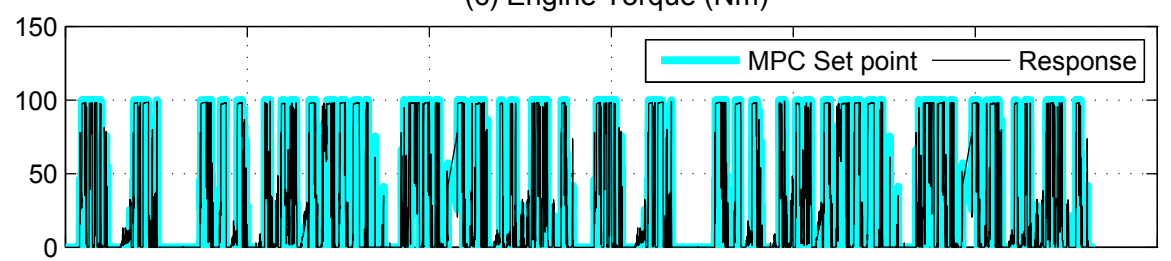

(d) Fuel Consumption (g)

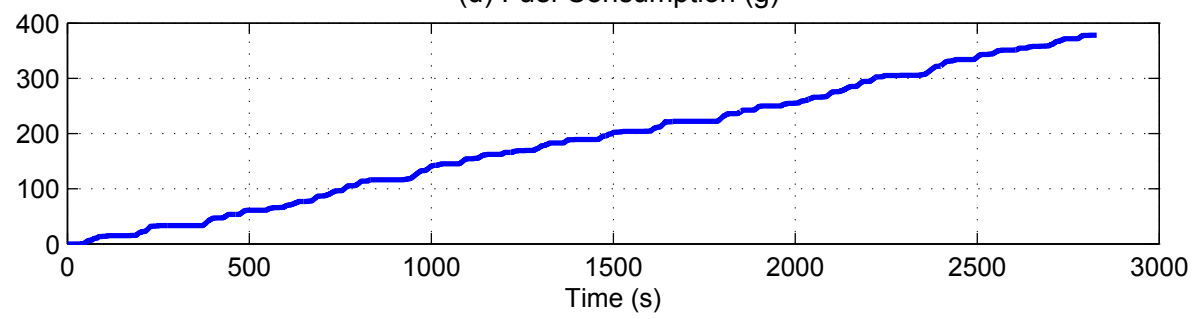

Fig. 6. Blended mode strategy with emissions control: (a) Velocity and battery SOC (b) MG-2 torque (c) Engine torque (d) Fuel consumption 
(a) CDCS Strategy with Emission Control

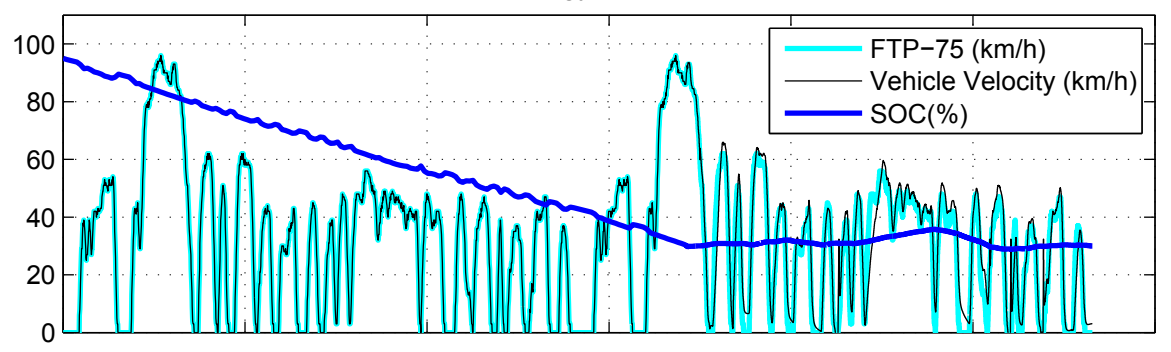

(b) MG2 Torque (Nm)

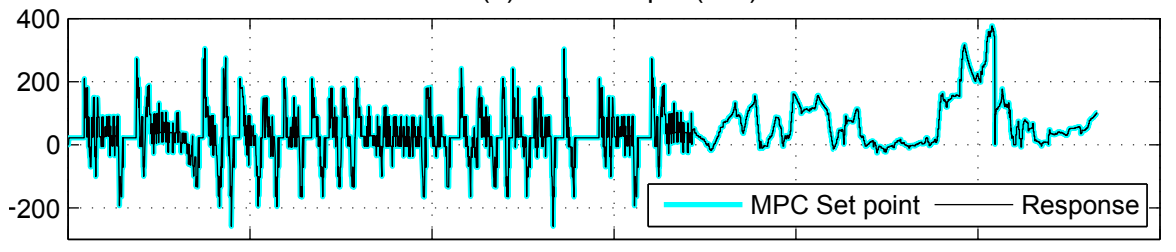

(c) Engine Torque (Nm)

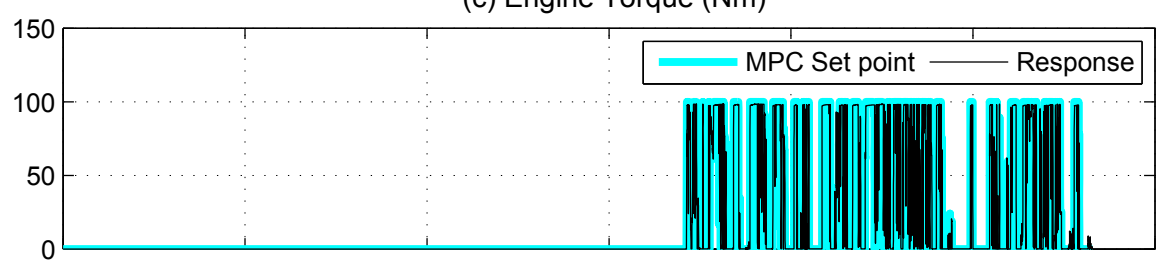

(d) Fuel Consumption (g)

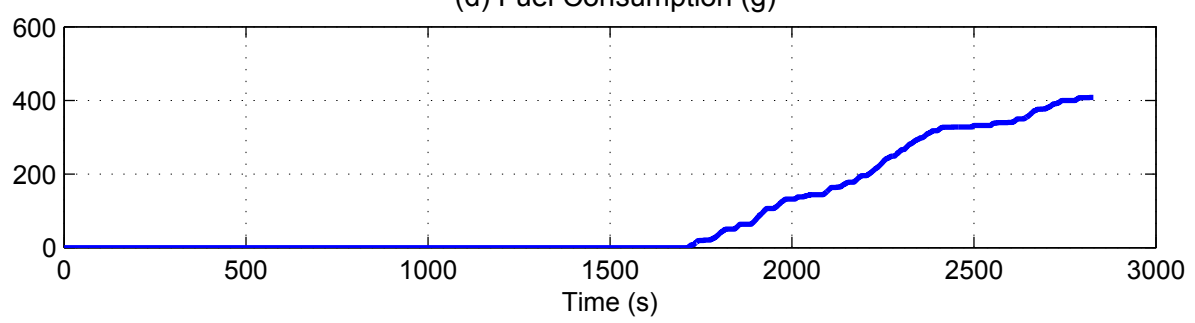

Fig. 7. CDCS strategy with emission control: (a) Velocity and battery SOC (b) MG-2 torque (c) Engine torque (d) Fuel consumption 
(a) Ignition Timing after TDC (deg)

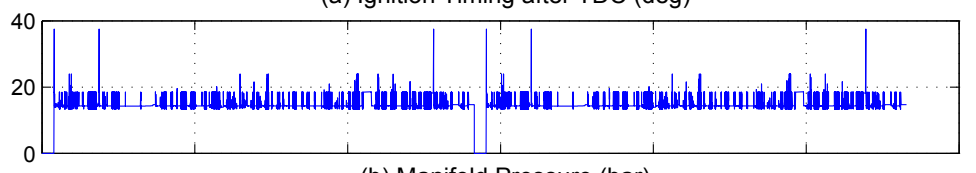

(b) Manifold Pressure (bar)

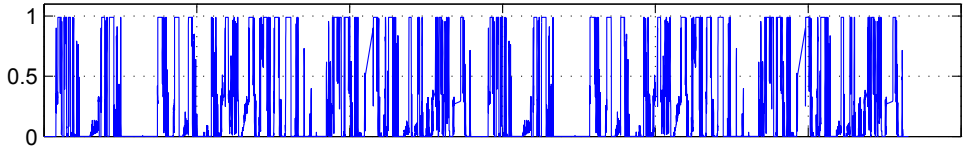

(c) Air to Fuel Ratio

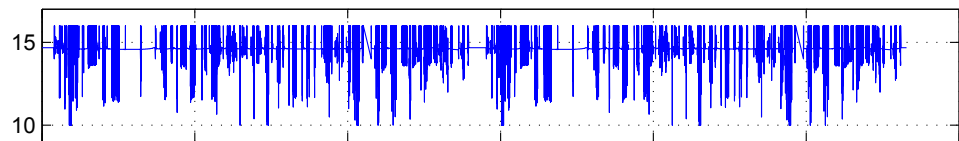

(d) Conversion Efficiency

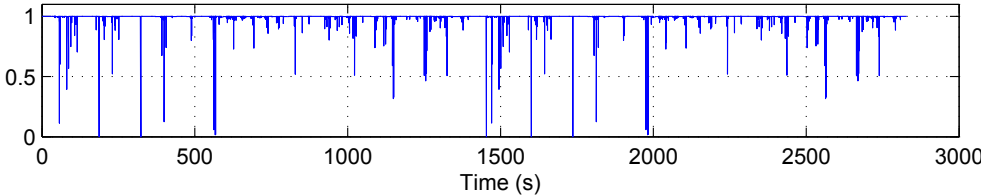

Fig. 8. Blended mode strategy with emissions control: (a) Ignition timing (b) Manifold pressure (c) AFR (d)Conversion efficiency

(a) Ignition Timing after TDC (deg)

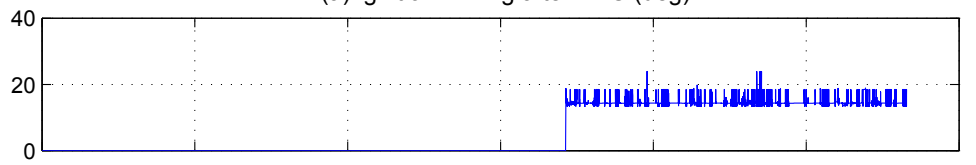

(b) Manifold Pressure (bar)

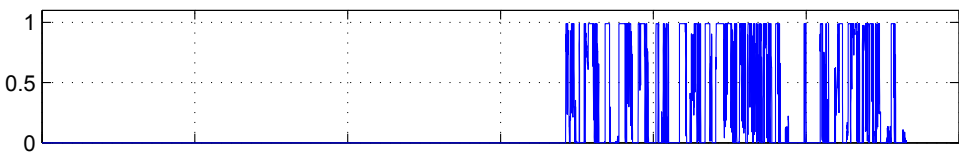

(c) Air to Fuel Ratio

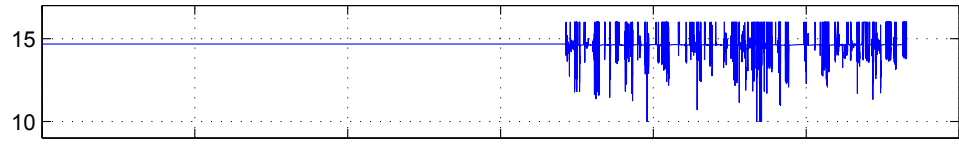

(d) Conversion Efficiency

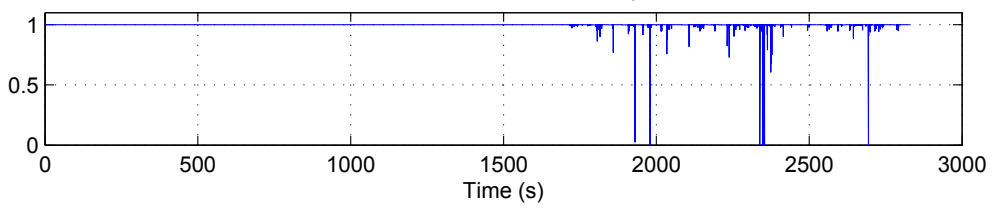

Fig. 9. CDCS strategy with emissions control: (a) Ignition timing (b) Manifold pressure (c) AFR (d) Conversion efficiency 
(a) CDCS strategy

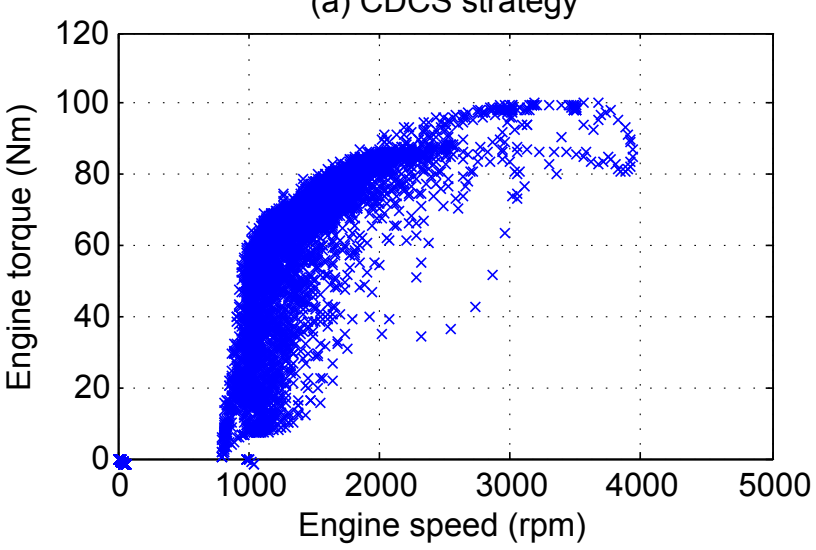

(b) Blended mode strategy

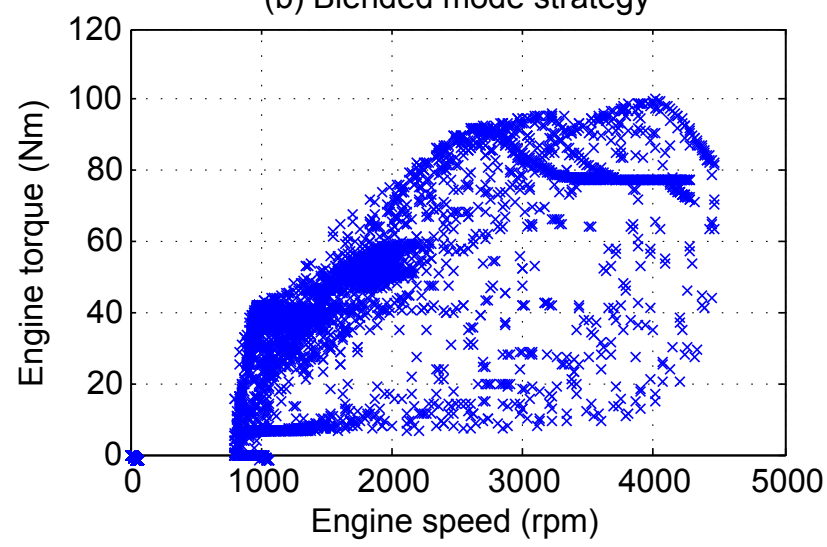

Fig. 10. Engine operating points for (a) CDCS (b) Blended mode strategies

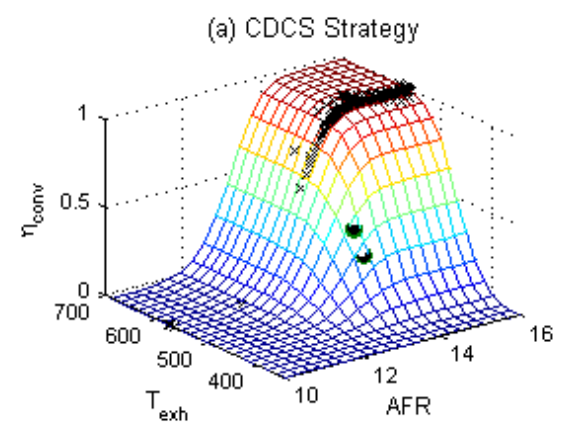

(b) Blended Mode Strategy

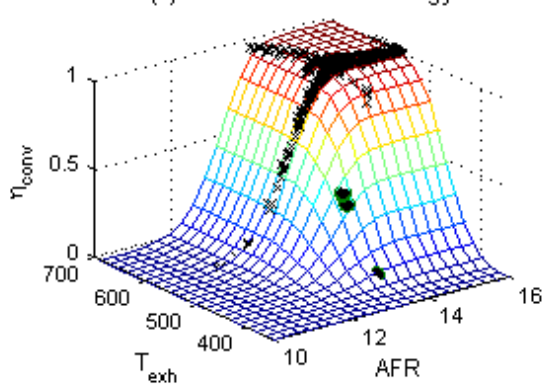

Fig. 11. Catalyst conversion efficiency for (a) CDCS (b) Blended mode strategies: without emission control(bullet marker)/with emission control (times marker) 